\title{
Current Status of the Application of the Empowerment Theory in Patients with Chronic Obstructive Pulmonary Disease
}

\author{
Yanmei Wu1 ${ }^{1}$, Ling Zhang2, Xiaochun Peng1* \\ ${ }^{1}$ Medical School of Yangtze University, Jingzhou, China \\ ${ }^{2}$ Nursing Department of First Affiliated Hospital of Yangtze University, Jingzhou, China \\ Email: *wym03050601@sina.com
}

How to cite this paper: Wu, Y.M., Zhang, L. and Peng, X.C. (2019) Current Status of the Application of the Empowerment Theory in Patients with Chronic Obstructive Pulmonary Disease. Yangtze Medicine, 3, 212-224.

https://doi.org/10.4236/ym.2019.33021

Received: March 28, 2019

Accepted: June 25, 2019

Published: June 28, 2019

Copyright () 2019 by author(s) and Scientific Research Publishing Inc. This work is licensed under the Creative Commons Attribution International License (CC BY 4.0).

http://creativecommons.org/licenses/by/4.0/

\begin{abstract}
Chronic obstructive pulmonary disease (COPD) has become a public health problem, and it can't be cured. In addition, patients with COPD are often passive in coping with health education. Empowerment theory emphasizes authorization for the patients, and gets them involved so as to improve the level of disease participation and disease management of them, just make up the current shortage. There are many foreign studies on the theory of empowerment about COPD, and the empowerment measurement tools are diversified. But there are fewer related researches in China. Therefore, this paper reviews the application of empowerment theory in COPD patients in terms of its definition, measuring tools, application in patients with COPD and influential factors affecting empowerment in patients with COPD in order to provide a new perspective for COPD research in China.
\end{abstract}

\section{Keywords}

COPD, Empowerment Theory, Application, Review

\section{Introduction}

COPD is a progressive chronic lung disease with irreversible airflow constraints, and the course of the disease is long and progressive. At present, the incidence of COPD is increasing, with the global prevalence of $11.7 \%$ [1], high disability rate [2] [3] and high genetic [4] [5] have been proven. In addition, the co-existence of COPD in other chronic diseases increases the risk of death from related diseases [6]. COPD requires long-term medication, although drugs can optimize airway function and alleviate symptoms, they cannot eliminate the psychological 
effects, which include depression and anxiety, social isolation, loss of independence and the damage of self-esteem, etc. At present, at least half of COPD patients have not acquired any diagnosis before serious damage occurs [7], leading to the not optimistic current situation about self-management of COPD patients. Currently, related theories which used in patients with COPD disease management mainly include Bandura Learning theory [8], Self-efficacy theory [9], Cross-theoretical model [10] [11] and so on. Mostly the quality of patients' life can be improved by health education, but the intervention measures only remain at the education level. The latest edition of the guidelines for the diagnosis and treatment of COPD points out that the treatment of stable COPD patients mainly includes drug treatment and non-drug treatment, among which non-drug treatment includes health education and self-management, exercise, lung rehabilitation and so on [Figure 1]. However, it is clear that the traditional health education cannot change patients' behaviors, or even achieve the goal of motivating patients. At the same time, it is pointed out that education and self-management should exist simultaneously. Empowerment theory emphasizes the co-creation of knowledge, not just the passive transfer of knowledge, and stresses the participation process of patients [12], which makes up the deficiency of current research. At present, the research of the empowerment theory in COPD patients is far behind that of other chronic diseases [13] [14]. However, good self-management after empowerment has been regarded as the key to prevent disease progression [15]. Moreover, the application of the empowerment

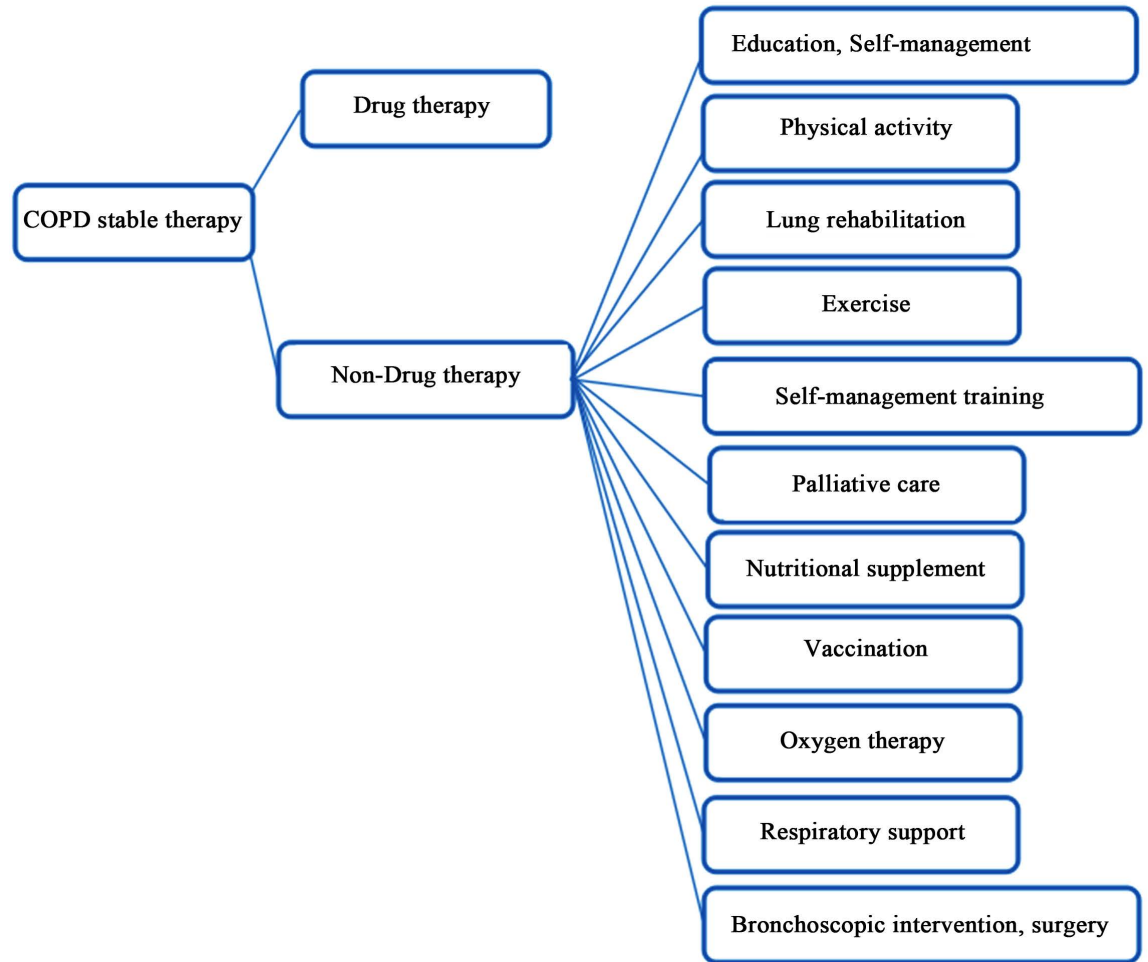

Figure 1. The latest edition of COPD diagnosis and treatment guide-COPD stabl e therapy https://goldcopd.org/. 
theory in stroke, hypertension and diabetes has also proved that empowerment can improve patients' ability of disease management and quality of life. In this paper, we expound the application progress of the empowerment theory in patients with COPD, in order to provide reference for the long-term study of COPD.

\section{Definition of Empowerment}

Empowerment originated in the last century. It is divided into social empowerment and psychological empowerment, especially emphasis on self-awareness and individual potential [16]. In clinical nursing practice, it is often referred to as "empowerment" or "authorization". Under the great influence of Carl Rogers' humanism, most of the nursing practices focusing on psychological empowerment. At present, the concept has been blurred and extended due to the free use [17], Fotokian, Shahboulaghi, Fallahi-Khoshknab, and Pourhabib [18] think empowerment is a dynamic and creative process for patients, the series of adaptations made by the patients after they are empowered and they have a high degree of autonomy, but it also emphasizes dependence on the help of others, which is an interactive concept.

\section{Application Status of Empowerment Tools at Home and Abroad}

The application of appropriate empowerment measurement tools can directly evaluate the effect of patients' empowerment. So necessary empowerment tools are also indispensable in the process of patients' empowerment. Sun and Jiang [19] described in detail 18 empowerment measurement tools at home and abroad, which were applied to different disease. At present, empowerment measurement tools are widely used in foreign countries, but not all of them have been applied in China due to the differences of regions and research objects. In China, The Diabetes Empowerment Scale-short Form (DES) [20] [21]. The Elders Health Empowerment Scale (HES) [22] and The Chinese version of The Empowerment Scale for patients with chronic diseases [23] have been well developed with well reliability and validity. In addition, Zhang and Li [24] in China also developed a questionnaire for the measurement of empowerment in patients with stroke, which was proved to have stable internal consistency. However, the empowerment related measurement tools for patients with COPD mainly include Patient Activation Measure (PAM), and there are 13 clauses of them, Cronbach's alpha was 0.88 , which has not been translated into Chinese, and there is no systematic empowerment measurement tool of COPD in China.

\section{Application and Effect of Empowerment Theory in COPD Patients}

In terms of the literature, although they all have their own priorities, they are interrelated. And the ways and contents of empowerment are different, which involve patients in many aspects of disease management [Table 1], such as smoking 
Table 1. Application and effect of empowerment theory in COPD patients.

\begin{tabular}{|c|c|c|c|c|}
\hline Apply & Author & Patient & Method & Result \\
\hline \multirow[t]{2}{*}{$\begin{array}{l}\text { Etiological } \\
\text { prevention }\end{array}$} & Kaptain & $\begin{array}{c}100 \\
\text { outpatients }\end{array}$ & Fill in the B-IPQ and drawing lung & $\begin{array}{l}\text { B-IPQ reflects patients' optimism about } \\
\text { the consequences of COPD, } 87 \text { patients } \\
\text { completed the drawing and believed } \\
\text { that COPD was related to smoking } \\
\text { quit smoking theme }\end{array}$ \\
\hline & Wenter & $\begin{array}{l}398 \text { users on the } \\
\text { COPD website }\end{array}$ & $\begin{array}{l}\text { The researchers analyzed topics } \\
\text { based on the patients' posts on the site. } \\
\text { And interact with patients. }\end{array}$ & \\
\hline \multirow[t]{2}{*}{ Exercise } & Dobbels & $\begin{array}{l}116 \text { from } \\
\text { four countries }\end{array}$ & Three consecutive qualitative studies & $\begin{array}{l}\text { A conceptual framework for exercise was } \\
\text { developed. Patients really understand the } \\
\text { importance of physical activity. }\end{array}$ \\
\hline & Desveaux & 29 patients & Focus group method & $\begin{array}{l}\text { Identify the obstacles to the rehabilitation } \\
\text { of patients in the community, and } \\
\text { formulate a sound exercise intervention } \\
\text { pulmonary rehabilitation plan. }\end{array}$ \\
\hline \multirow[t]{3}{*}{ Breathing } & Koldkjaer & 9 patients & $\begin{array}{l}\text { An online respiratory rehabilitation } \\
\text { program was discussed by semi-structured } \\
\text { interview, patients point obstacles } \\
\text { about breathing exercises }\end{array}$ & $\begin{array}{l}\text { Respiratory exercise instruction and } \\
\text { Online focused counseling can benefit } \\
\text { citizens' participatory health }\end{array}$ \\
\hline & Jiang & 120 patients & $\begin{array}{l}60 \text { patients (Experimental group) were } \\
\text { trained in empowerment mode, The } \\
\text { remaining } 60 \text { patients (control group) } \\
\text { received routine oral education. }\end{array}$ & $\begin{array}{l}\text { The improvement of FEV1, FEV1/FVC } \\
\text { and PEF in the intervention group was } \\
\text { greater than that in the control group. }\end{array}$ \\
\hline & Zhang & 110 patients & $\begin{array}{l}55 \text { patients (Experimental group) underwent } \\
\text { an empowerment breathing training pattern, } \\
\text { The remaining } 55 \text { patients (control group) } \\
\text { received routine guidance }\end{array}$ & $\begin{array}{l}\text { Experimental group about lung function } \\
\text { improvement and self-efficacy were } \\
\text { better than the control group. }\end{array}$ \\
\hline \multirow[t]{2}{*}{ Readmission } & Collinsworth & 308 patients & $\begin{array}{l}154 \text { patients (Experimental group) } \\
\text { conducted CCC project education, } \\
\text { For example, discuss COPD symptoms, } \\
\text { nutritional interventions, etc. Follow-up calls } \\
\text { were made within one week, one month, } \\
\text { two months and six months after discharge; } \\
\text { The remaining } 154 \text { patients (control group) } \\
\text { received follow-up calls were made only } \\
6 \text { months after discharge. }\end{array}$ & $\begin{array}{l}\text { Follow-up was completed in } 37 \% \text { of the } \\
\text { trial group and } 29 \% \text { of the control group, } \\
\text { respectively. The results showed that the } \\
\text { CCC program improved the quality of } \\
\text { life of patients, but there was no } \\
\text { statistical significance in the } \\
\text { readmission rate of the two groups. }\end{array}$ \\
\hline & Lavesen & 224 patients & $\begin{array}{l}\text { Both the experimental group }(\mathrm{n}=112) \text { and } \\
\text { control group }(\mathrm{n}=112) \text { received a disease } \\
\text { awareness questionnaire one month after } \\
\text { discharge, and telephone follow-up was } \\
\text { conducted on the 30th and 84th days to } \\
\text { collect the readmission rate and mortality. }\end{array}$ & $\begin{array}{l}\text { There was no statistical significance in } \\
\text { the readmission rate of the two groups. } \\
\text { There was statistical significance only in } \\
\text { patients' assessment of symptoms of } \\
\text { their own disease. }\end{array}$ \\
\hline Telemedicine & Nissen & 14 patients & $\begin{array}{l}\text { Semi-structured interviews were conducted } \\
\text { with patients who participated in Net-COPD } \\
\text { (submission of weekly readings and regular } \\
\text { video) to understand patients' views on } \\
\text { telemedicine. }\end{array}$ & $\begin{array}{l}\text { Improving sense of security and } \\
\text { happiness. Because they know the } \\
\text { medical staff will monitor their condition. }\end{array}$ \\
\hline
\end{tabular}




\section{Continued}

\begin{tabular}{|c|c|c|c|c|}
\hline & Bond & 118 patients & $\begin{array}{l}\text { A questionnaire was conducted to evaluate } \\
\text { the use of the remote equipment after the } \\
\text { initial use and } 3 \text { months of use. Qualitative } \\
\text { interview of patients' views on the use of } \\
\text { remote devices. Equipped with telemedicine } \\
\text { equipment (indicating the patient's oxygen } \\
\text { saturation, blood pressure, body } \\
\text { temperature and weight, etc.) }\end{array}$ & $\begin{array}{l}41 \% \text { of patients }(\mathrm{n}=48) \text { completed the } \\
\text { questionnaire, and } 29 \text { patients were } \\
\text { interviewed qualitatively. Most patients } \\
\text { were satisfied with the remote device, } \\
\text { but some patients believed that they } \\
\text { have no support. }\end{array}$ \\
\hline & Lilholt & 60 patients & $\begin{array}{l}\text { Patients' experience of remote devices and } \\
\text { their general health were investigated } \\
\text { through questionnaires }\end{array}$ & $\begin{array}{l}43 \text { patients felt increased sense of security, } \\
37 \text { patients felt increased sense of control } \\
\text { by using the system, } 30 \text { patients felt } \\
\text { awareness of their symptoms, and } \\
16 \text { felt increased freedom. }\end{array}$ \\
\hline \multirow{4}{*}{ Site } & Luan & 20 patients & $\begin{array}{l}\text { WeChat platform was used to investigate the } \\
\text { changes of patients' self-measured health } \\
\text { before and after using remote devices }\end{array}$ & $\begin{array}{l}\text { Patients' self-test health awareness } \\
\text { was enhanced }\end{array}$ \\
\hline & $\mathrm{Li}$ & 8 patients & $\begin{array}{l}\text { The change of self-efficacy of patients before } \\
\text { and after using remote equipment was } \\
\text { investigated by questionnaire. }\end{array}$ & $\begin{array}{l}\text { The self-efficacy of patients with } \\
\text { remote devices was significantly enhanced }\end{array}$ \\
\hline & Wentzer & 398 patients & $\begin{array}{l}\text { The researchers analyzed topics } \\
\text { based on the patients' posts on the site. } \\
\text { And interact with patients. }\end{array}$ & $\begin{array}{l}\text { Online support groups are an } \\
\text { important resource for empowerment }\end{array}$ \\
\hline & $\mathrm{Lu}$ & 100 patients & $\begin{array}{l}\text { COPD diagnosis and treatment platform } \\
\text { was established based on the website, } \\
\text { where patients filled in screening } \\
\text { questionnaires and symptoms, and } \\
\text { outpatient visits were made to determine } \\
\text { their diagnosis and related treatment. }\end{array}$ & $\begin{array}{l}\text { Patients improve the ability of } \\
\text { disease awareness and management }\end{array}$ \\
\hline
\end{tabular}

cessation, exercise, breathing strategies, nursing in acute exacerbation period and psychological stress management. Medicine is changing from traditional medical practice to a positive and personalized discipline. Traditional medical and health care models are not suitable for chronic diseases [25]. This is because traditional health care models tend to address acute events with a disease-oriented approach, ignoring the patient's dominant position. Individualized medicine emphasizes the main status of patients [26], which is suitable for the management of chronic diseases. The theory of empowerment following the trend of personalized medicine, because the focus of empowerment theory is to empower patients and let them in an active position.

\subsection{Etiological Prevention}

The department of health clearly pointed out that quitting smoking could prevent and avoid exacerbation of COPD [27]. Kaptein, Tiemensma, Broadbent, Asijee, and Voorhaar [28] tested the feasibility of the innovative approach by asking people with COPD to draw pictures, the picture asked the patient to draw their cognitive lungs, accompanied by a short disease perception questionnaire (Brief-Illness Perception Questionnaire, B-IPQ) to assess patients' awareness of 
their disease, eighty-seven of them completed the drawing and believed that COPD was related to smoking and truly accepted to quit smoking. Similarly, Wenters and Bygholm [29] browsed COPD patients' communication posts on the site, finding smoking and exercise were the most talked about topics among the 398 patients, who said it was important to change habits and lifestyles and believed that quitting smoking and exercising could prolong their lives.

\subsection{Sports Guidance}

Maintaining a certain level of physical activity can be a challenge for patients with COPD, who may experience dyspnea during exercise and may bring about threats and embarrassment [30]. Therefore most COPD patients cannot coping with the limited activity level when the disease is aggravated. While physical activity is considered as an important target for COPD treatment. Dobbels et al. [31] conducted 3 consecutive qualitative studies on 116 patients, a conceptual framework of physical activity is established, in which patients understand the importance of physical activity and learn to recognize adverse symptoms that occur during activity. Desveaux et al. [30] conducted a 6 months study of "minimally supervised exercise intervention" in a community, in which 12 patients received exercise intervention for half a year. Patients realized the importance of exercise plan which not only improved physical health, but also improved psychological mood, and Identified the obstacles to the rehabilitation.

\subsection{Respiratory Exercise}

For patients with COPD, respiratory exercise is an extremely important form of lung rehabilitation. Koldkjaer, Caroe, Lindgren, and Mathiesen [32] conducted respiratory counseling and training for patients with moderate and severe COPD, working out the specific needs of patients and greatly alleviating their anxiety caused by dyspnea. In China, Jiang [33] significantly improved patients' lung function and self-efficacy through empowerment education training. Similarly, Zhang and Luo [34] also showed that the 6-month training of empowerment breathing also improved the self-efficacy of COPD patients. This demonstrates the relevant researchers proposed that drugs cannot solve the psychological problems of patients [35].

\subsection{Readmission Rates}

Because the characteristic of relapse, so the study of the readmission rate of COPD patients has also been paid more attention. Collins worth et al. [36] assessed the feasibility of a long-term care education program for COPD and determined whether the program affected the readmission rate of patients. Although result proved the feasibility of the education program and improved patients' knowledge, there was no significant statistical difference between the two groups in readmission rate. Lavesen, Ladelund, Frederiksen, Lindhardt, and Overgaard [37] conducted similar study, discussing whether discharged COPD patients can improve their awareness and reduce readmission rate through tele- 
phone follow-up. The result also showed that not reduce the patients with COPD readmission rate.

\subsection{The Application of Telemedicine}

At present, telemedicine is widely used for chronic diseases, but it is still a neglected field as an empowerment tool [38]. It is undeniable that telemedicine has shown great potential in increasing patients' rights [39] [40].

Nissen and Lindhardt [41] conducted a six-month telemedicine intervention study, through the remote device to receive timely feedback about health of the patients. According to the feedback results, the necessary coping strategies were given to the patients. In the process, Patients gain a sense of control and security over their illness. Bond [38] also found similar results, some patients believed that they are involved in medical decisions, but some patients thought the use of the remote device to be a burden for them. This is understandable, because it can be difficult for COPD patients to detect and respond appropriately to worsening conditions. And that the details were worked out by the nurse and patient is still in a passive position, the hoped-for "participatory health" into a "medical paternalism". Relevant studies [29] also prove this point, the researcher thought most of the current studies described relationship of empowerment between doctors and patients as "authorization" and "obedience", ignoring the patient's subject status in the process of empowering. Lilholt, Haesum, and Hejlesen [42] have also proved that telemedicine can improve ability of disease management, but the difference is that It's a pure quantitative study. In China, relevant studies conducted by Luan [43] and Li [44] have also confirmed that telemedicine has great benefits in self-management and self-efficacy of COPD patients.

The effects of telemedicine devices are considerable. A common feature of these studies is that as patients spend more time using telemedicine devices, their disease management ability, quality of life and emotional improvement also increase. Rixon et al. [45] also demonstrated the viewpoint.

\subsection{Website Communication}

The development of the Internet has provided a new platform for empowerment. Through online conversations with 398 COPD patients, Wentzer and Bygholm [29] concluded that online support group was an important resource for empowerment, and developed corresponding coping strategies based on the most talked about topics (smoking cessation and rehabilitation courses).Lu and Zheng [46] developed a network platform for patient of COPD, although the purpose was to confirm whether the relevant volunteers were COPD patients, patients actively participated in this process during the collection of disease information and improved their disease management ability.

\section{Factors Influencing the Empowerment of Patients with COPD}

Although a lot of researches shown that empowerment can improve patientsa- 
bility of disease management, not all patients respond to empowerment in this process [47]. In other words, the level of receive empowerment depends on their participation about health issues [48]. If only empowering rights of patients without evaluation, it may lead to the aggravation of the patient's illness and even death [49]. Therefore, "patient activation" is also the focus of many researchers, most of whom measure the activation degree and ability of patients after empowerment through the PAM-13 scale.

Studies indicated that relevant factors mainly include psychological factors (such as not wanting to face the occurrence or aggravation of the disease), no experience in coping with the disease, and lack of external support, but external support is also proposed as a contributing factor [50] [51] [52]. Mullerova et al. [53] concluded that high expectations of disease, poor health, and low satisfaction with health care workers are also barriers. Stoilkova-Hartmann, Franssen, Augustin, Wouters, and Barnard [54] further refined the obstacles in the process of disease management, such as social support, environment and lifestyle in external factors, health belief and internal motivation in internal factors [Table 2]. The results of these studies suggest that the quality of life and self-management of disease in patients with COPD are dependent on the individual's condition after empowerment.

\section{Summary}

From the above, empowerment theory is a process in which patients gain the ability to cope with diseases and improve their sense of self-efficacy and have necessary knowledge, skills and attitudes. In addition, the empowerment process emphasizes patient involvement. More and more attention has been paid to the application of empowerment theory in patients with COPD. In view of the current situation, the following outlook is proposed:

At present, the measurement tools for chronic diseases are diversified, and it's applied to different specialist areas. Since most of them are introduced from foreign countries, we need to verify whether they are practical in application. PAM-13

Table 2. Influencing factors of COPD patient empowerment.

\begin{tabular}{|c|c|c|c|}
\hline Author & Patient & Method & Influence factor \\
\hline Halding & 116 patients & $\begin{array}{l}\text { Cross-sectional } \\
\text { study }\end{array}$ & $\begin{array}{l}\text { Individual differences, } \\
\text { psychological factors }\end{array}$ \\
\hline Hillebregt & 46 patients & Questionnaire & $\begin{array}{c}\text { Lack of experience, } \\
\text { Lack of support }\end{array}$ \\
\hline Roberts & $\begin{array}{c}\text { Patients in } 4 \text { sample } \\
\text { datasets }\end{array}$ & PAM-13 scale & $\begin{array}{c}\text { Lack of external support, } \\
\text { healthy state }\end{array}$ \\
\hline Mullerova & 4343 patients & $\begin{array}{l}\text { Cross-sectional } \\
\text { study }\end{array}$ & $\begin{array}{l}\text { High expectations of disease, } \\
\text { poor health, lowsatisfaction }\end{array}$ \\
\hline Stoilkova-Hartmann & $\begin{array}{l}13 \text { pulmonary } \\
\text { rehabilitation personnel }\end{array}$ & CS-PAM scale & $\begin{array}{l}\text { Social support, health belief, } \\
\text { environment and lifestyle, } \\
\text { internal motivation }\end{array}$ \\
\hline
\end{tabular}


is widely used in foreign countries for COPD empowerment measurement tools, but it has not been sinicized at present, which is a direction of future research. In addition, in the process of using and developing the scale, the influencing factors of empowerment should be fully considered. A large number of studies are still needed to explore which factors can be corrected, and then improve patients' ability to accept empowerment and enjoy a higher quality of life. In the study, we should pay attention to the heterogeneity of patient characteristics and formulate different intervention measures according to different characteristics.

Empowerment has a significant effect on the etiology prevention, exercise, breathing exercise, telemedicine and website communication about COPD patients. Considering the complexity, repetition, and progressiveness of COPD, empowerment had little effect on readmission rates, only shortened the readmission time. We need more comprehensive disease management programme to improve outcomes in the future. In order to adapt to the economic restructuring, chronic disease management is particularly important. But due to the heterogeneity of COPD, we must take into account the impact of a patient's unique environment when caring for them. COPD patients still need regular outpatient follow-up in the stable stage of the disease, so as to detect the progress of the disease, but it also causes increased pressure on outpatient visits. As a new empowerment tool, telemedicine reduces the pressure on the number of patients in medical departments and optimizes the health resources, which is the trend of smart medical research and direction of future research. Besides, monitoring the use of telemedicine is extremely important, because we don't just keep track of the data, we need to make professional judgments about the progress of the disease. The expertise of professionals is the lifeblood of remote device use, which cannot be ignored in future studies.

\section{Acknowledgements}

This study was supported by Hubei Natural Science Fund Project (2017CFB786).

\section{Conflicts of Interest}

The authors declare no conflicts of interest regarding the publication of this paper.

\section{References}

[1] Wang, L., Martensson, J., Zhao, Y. and Nygardh, A. (2018) Experiences of a Health Coaching Self-Management Program in Patients with COPD: A Qualitative Content Analysis. International Journal of Chronic Obstructive Pulmonary Disease, 13, 1527-1536. https://doi.org/10.2147/COPD.S161410

[2] Shafuddin, E., Chang, C.L., Cooray, M., McAnulty, K.A., Karalus, N.C., Lee, M. and Hancox, R.J. (2018) Cardiac Dysfunction in Exacerbations of Chronic Obstructive Pulmonary Disease Is Often Not Detected by Electrocardiogram and Chest Radiographs. Internal Medicine Journal. https://doi.org/10.1111/imj.14144

[3] Lipworth, B., Wedzicha, J., Devereux, G., Vestbo, J. and Dransfield, M.T. (2016) 
Beta-Blockers in COPD: Time for Reappraisal. The European Respiratory Journal, 48, 880-888. https://doi.org/10.1183/13993003.01847-2015

[4] Li, L.S., Paquet, C., Johnston, K. and Williams, M.T. (2017) What Are My Chances of Developing COPD If One of My Parents Has the Disease? A Systematic Review and Meta-Analysis of Prevalence of Co-Occurrence of COPD Diagnosis in Parents and Offspring. International Journal of Chronic Obstructive Pulmonary Disease, 12, 403-415. https://doi.org/10.2147/COPD.S123933

[5] Cannon, D., Buys, N., Sriram, K.B., Sharma, S., Morris, N. and Sun, J. (2016) The Effects of Chronic Obstructive Pulmonary Disease Self-Management Interventions on Improvement of Quality of Life in COPD Patients: A Meta-Analysis. Respiratory Medicine, 121, 81-90. https://doi.org/10.1016/j.rmed.2016.11.005

[6] Figueira, G.J., Martin, M.M., Perez, M.L., Garcia, B.M., Garcia-Talavera, I., Hernandez, S.G., Diaz, P.D. and Bethencourt, M.N. (2018) Health Status in Patients with COPD According to GOLD 2017 Classification: Use of the COMCOLD Score in Routine Clinical Practice. COPD, 15, 326-333. https://doi.org/10.1080/15412555.2018.1531388

[7] Enocson, A., Jolly, K., Jordan, R.E., Fitzmaurice, D.A., Greenfield, S.M. and Adab, P. (2018) Case-Finding for COPD in Primary Care: A Qualitative Study of Patients' Perspectives. International Journal of Chronic Obstructive Pulmonary Disease, 13, 1623-1632. https://doi.org/10.2147/COPD.S147718

[8] Xia, Y., Chen, Y., Wu, J.F., Wu, J., Guo, Q. and Xiong, H. (2011) Influence of Bandura Learning Theory on Recognition of Patients with COPD. Chinese Nursing Research, 25, 3349-3350.

[9] Huang, H. and Ou, Y.Y. (2017) Effect of Self-Management Intervention Based on Self-Efficacy Theory in Patient with Chronic, Obstructive Pulmonary Disease. Journal of Bengbu Medical College, 42, 1696-1700.

[10] Chen, X., Yang, X.Y. and Liu, S.M. (2018) Effects of Rehabilitation Exercise Intervention on the Pulmonary Function and Quality of Life in Patients with Chronic Obstructive Pulmonary Disease Based on Trans-Theoretical Model. Chinese General Practice, 21, 3240-3245.

[11] Shen, J. and Zhao, W.F. (2018) Effects of Cross-Theoretical Models on Respiratory Exercise and Self-Management in Patients with Chronic Obstructive Pulmonary Disease. Journal of Nurses Training, 33, 849-851.

[12] Castro, E.M., Van Regenmortel, T., Vanhaecht, K., Sermeus, W. and Van Hecke, A. (2016) Patient Empowerment, Patient Participation and Patient-Centeredness in Hospital Care: A Concept Analysis Based on a Literature Review. Patient Education and Counseling, 99, 1923-1939. https://doi.org/10.1016/j.pec.2016.07.026

[13] Gong, B.X. and Fu, W. (2016) Research Progress on the Empowerment of Patients with Chronic Diseases in China. Chinese Journal of Social Medicine, 33, 532-535.

[14] Kaptein, A.A., Fischer, M.J. and Scharloo, M. (2014) Self-Management in Patients with COPD: Theoretical Context, Content, Outcomes, and Integration into Clinical Care. International Journal of Chronic Obstructive Pulmonary Disease, 9, 907-917. https://doi.org/10.2147/COPD.S49622

[15] Robinson, K., Lucas, E., van den Dolder, P. and Halcomb, E. (2018) Living with Chronic Obstructive Pulmonary Disease: The Stories of Frequent Attenders to the Emergency Department. Journal of Clinical Nursing, 27, 48-56. https://doi.org/10.1111/jocn.13842

[16] Ou, Y.J. and Jiang, H.R. (2018) Research on the Application of Empowerment Theory in Patient Health Education. Chinese Nursing Research, 32, 1001-1004. 
[17] Jerofke, T.A. (2013) Concept Analysis of Empowerment from Survivor and Nurse Perspectives within the Context of Cancer Survivorship. Research and Theory for Nursing Practice, 27, 157-172. https://doi.org/10.1891/1541-6577.27.3.157

[18] Fotokian, Z., Shahboulaghi, F.M., Fallahi-Khoshknab, M. and Pourhabib, A. (2017) The Empowerment of Elderly Patients with Chronic Obstructive Pulmonary Disease: Managing Life with the Disease. PLoS ONE, 12, e0174028. https://doi.org/10.1371/journal.pone.0174028

[19] Sun, Y.Q. and Jiang, A.L. (2017) Advances in Research on Empowerment Measurement Tools for Patients with Chronic Diseases. Chinese Journal of Nursing, 52, 481-485.

[20] Qi, M.M. and Li, Z.K. (2016) The Development and Application of Empowerment Tools for Patients and Their Families. Chinese Nursing Research, 30, 2318-2321.

[21] Hu, B.B. (2010) A Preliminary Study on the Revision and Application of Simplified Chinese Diabetes Scale. Zhejiang University, Hangzhou.

[22] Lei, M.J., Liu, Y.Q., Zhang, C.M., Liu, T.T., Meng, L.N., Sang, M. and Jin, C.D. (2018) Reliability and Validity of the Chinese Version of the Simplified Elders Health Empowerment Scale. Journal of Nursing Science, 33, 83-85.

[23] Li, X. (2017) Chinese Revision of Chronic Disease Aptitude Scale and Reliability and Validity Study in Elderly Patients in Community. Southern Medical University, Guangzhou.

[24] Zhang, X.B. and Li, B.E. (2014) The Development, Reliability and Validity Test of the Evaluation Scale for Stroke Patients with Empowerment Nursing. Chinese Nursing Management, 29, 30-33.

[25] Hernandez, C., Alonso, A., Garcia-Aymerich, J., Serra, I., Marti, D., Rodriguez-Roisin, R., Narsavage, G., Carmen, G.M. and Roca, J. (2015) Effectiveness of Community-Based Integrated Care in Frail COPD Patients: A Randomised Controlled Trial. NPJ Primary Care Respiratory Medicine, 25, 15022.

https://doi.org/10.1038/npjpcrm.2015.22

[26] Phanareth, K., Vingtoft, S., Christensen, A.S., Nielsen, J.S., Svenstrup, J., Berntsen, G.K.R., Newman, S.P. and Kayser, L. (2017) The Epital Care Model: A New Person-Centered Model of Technology-Enabled Integrated Care for People with Long Term Conditions. JMIR Research Protocols, 6, e6. https://doi.org/10.2196/resprot.6506

[27] Lim, T.K., Chee, C.B., Chow, P., Chua, G., Eng, S.K., Goh, S.K., Kng, K.K., Lim, W.H., Ng, T.P., Ong, T.H., Seah, S., Tan, H.Y., Tee, K.H., Palanichamy, V. and Yeung, M.T. (2018) Ministry of Health Clinical Practice Guidelines: Chronic Obstructive Pulmonary Disease. Singapore Medical Journal, 59, 76-86. https://doi.org/10.11622/smedj.2018015

[28] Kaptein, A.A., Tiemensma, J., Broadbent, E., Asijee, G.M. and Voorhaar, M. (2017) COPD Depicted-Patients Drawing Their Lungs. International Journal of Chronic Obstructive Pulmonary Disease, 12, 3231-3236.

https://doi.org/10.2147/COPD.S139896

[29] Wentzer, H.S. and Bygholm, A. (2013) Narratives of Empowerment and Compliance: Studies of Communication in Online Patient Support Groups. International Journal of Medical Informatics, 82, e386-e394. https://doi.org/10.1016/j.ijmedinf.2013.01.008

[30] Desveaux, L., Rolfe, D., Beauchamp, M., Goldstein, R. and Brooks, D. (2014) Participant Experiences of a Community-Based Maintenance Program Post-Pulmonary Rehabilitation. Chronic Respiratory Disease, 11, 23-30. 
https://doi.org/10.1177/1479972313516880

[31] Dobbels, F., de Jong, C., Drost, E., Elberse, J., Feridou, C., Jacobs, L., Rabinovich, R., Frei, A., Puhan, M.A., de Boer, W.I., van der Molen, T., Williams, K., Pinnock, H., Troosters, T., Karlsson, N., Kulich, K. and Rudell, K. (2014) The PROactive Innovative Conceptual Framework on Physical Activity. The European Respiratory Journal, 44, 1223-1233. https://doi.org/10.1183/09031936.00004814

[32] Koldkjaer, S.I., Caroe, P., Lindgren, K. and Mathiesen, K.S. (2015) Online Communication and Chronic Obstructive Pulmonary Disease (COPD). Studies in Health Technology and Informatics, 216, 910.

[33] Jiang, J.M. (2016) The Application of Empowerment Mode Training in COPD Patients Self-Management Skills. Nursing Practice and Research, 13, 7-9.

[34] Zhang, D.F. and Luo, C.F. (2014) Effects of Incapacitating Respiratory Rehabilitation Training on Self-Efficacy in Patients with Chronic Obstructive Pulmonary Disease. Guangdong Medical Journal, 35, 3932-3933.

[35] Early, F., Young, J.S., Robinshaw, E., Mi, E.Z. and Fuld, J.P. (2017) A Case Series of an Off-the-Shelf Online Health Resource with Integrated Nurse Coaching to Support Self-Management in COPD. International Journal of Chronic Obstructive Pulmonary Disease, 12, 2955-2967. https://doi.org/10.2147/COPD.S139532

[36] Collinsworth, A.W., Brown, R.M., James, C.S., Stanford, R.H., Alemayehu, D. and Priest, E.L. (2018) The Impact of Patient Education and Shared Decision Making on Hospital Readmissions for COPD. International Journal of Chronic Obstructive Pulmonary Disease, 13, 1325-1332. https://doi.org/10.2147/COPD.S154414

[37] Lavesen, M., Ladelund, S., Frederiksen, A.J., Lindhardt, B.O. and Overgaard, D. (2016) Nurse-Initiated Telephone Follow-Up on Patients with Chronic Obstructive Pulmonary Disease Improves Patient Empowerment, But Cannot Prevent Readmissions. Danish Medical Journal, 63, pii: A5276.

[38] Bond, C.S. (2014) Telehealth as a Tool for Independent Self-Management by People Living with Long Term Conditions. Studies in Health Technology and Informatics, 206, 1-6.

[39] Cruz, J., Brooks, D. and Marques, A. (2014) Home Telemonitoring Effectiveness in COPD: A Systematic Review. International Journal of Clinical Practice, 68, 369-378. https://doi.org/10.1111/ijcp.12345

[40] Haesum, L.K., Ehlers, L. and Hejlesen, O.K. (2013) Telehomecare Technologies Enhance Self-Management and Empowerment among Patients with Chronic Obstructive Pulmonary Disease (COPD) - Where Does Health Literacy Fit into This Equation? Studies in Health Technology and Informatics, 192, 1182.

[41] Nissen, L. and Lindhardt, T. (2017) A Qualitative Study of COPD-Patients' Experience of a Telemedicine Intervention. International Journal of Medical Informatics, 107, 11-17. https://doi.org/10.1016/j.ijmedinf.2017.08.004

[42] Lilholt, P.H., Haesum, L.K. and Hejlesen, O.K. (2015) Exploring User Experience of a Telehealth System for the Danish TeleCare North Trial. Studies in Health Technology and Informatics, 210, 301-305.

[43] Luan, Q.H. (2017) Effects of Telemedicine on Self-Measured Health of Patients with Stable COPD. Shandong University, Jinan.

[44] Li, J. (2016) Effects of Telemedicine on Self-Efficacy of Patients with Chronic Obstructive Pulmonary Disease in Home Wards. Shandong University, Jinan.

[45] Rixon, L., Hirani, S.P., Cartwright, M., Beynon, M., Doll, H., Steventon, A., Henderson, C. and Newman, S.P. (2017) A RCT of Telehealth for COPD Patient's Qual- 
ity of Life: The Whole System Demonstrator Evaluation. The Clinical Respiratory Journal, 11, 459-469. https://doi.org/10.1111/crj.12359

[46] Lu, H.N., Zheng, Z.G., Liu, N., Wang, X.N., Zhou, R.X. and Chen, R.C. (2016) Discussion on the Application of Network-Assisted Diagnosis and Treatment Platform for Chronic Obstructive Pulmonary Disease. Chinese General Medicine, 19, 3799-3802.

[47] Korpershoek, Y., Bos-Touwen, I.D., de Man-van, G.J., Lammers, J.W., Schuurmans, M.J. and Trappenburg, J. (2016) Determinants of Activation for Self-Management in Patients with COPD. International Journal of Chronic Obstructive Pulmonary Disease, 11, 1757-1766. https://doi.org/10.2147/COPD.S109016

[48] Luhr, K., Holmefur, M., Theander, K. and Eldh, A.C. (2018) Patient Participation during and after a Self-Management Programme in Primary Healthcare-The Experience of Patients with Chronic Obstructive Pulmonary Disease or Chronic Heart Failure. Patient Education and Counseling, 101, 1137-1142. https://doi.org/10.1016/j.pec.2017.12.020

[49] Sohanpal, R., Epiphaniou, E. and Taylor, S. (2014) Self-Management for COPD? Why Does It Generate Negative Connotations? British Journal of General Practice, 64, e522-e524. https://doi.org/10.3399/bjgp14X681157

[50] Halding, A.G. and Grov, E.K. (2017) Self-Rated Health Aspects among Persons Living with Chronic Obstructive Pulmonary Disease. International Journal of Chronic Obstructive Pulmonary Disease, 12, 1163-1172. https://doi.org/10.2147/COPD.S129325

[51] Hillebregt, C.F., Vlonk, A.J., Bruijnzeels, M.A., van Schayck, O.C. and Chavannes, N.H. (2017) Barriers and Facilitators Influencing Self-Management among COPD Patients: A Mixed Methods Exploration in Primary and Affiliated Specialist Care. International Journal of Chronic Obstructive Pulmonary Disease, 12, 123-133. https://doi.org/10.2147/COPD.S103998

[52] Roberts, N.J., Kidd, L., Dougall, N., Patel, I.S., McNarry, S. and Nixon, C. (2016) Measuring Patient Activation: The Utility of the Patient Activation Measure within a UK Context-Results from Four Exemplar Studies and Potential Future Applications. Patient Education and Counseling, 99, 1739-1746.

https://doi.org/10.1016/j.pec.2016.05.006

[53] Mullerova, H., Landis, S.H., Aisanov, Z., Davis, K.J., Ichinose, M., Mannino, D.M., Maskell, J., Menezes, A.M., van der Molen, T., Oh, Y.M., Tabberer, M. and Han, M.K. (2016) Health Behaviors and Their Correlates among Participants in the Continuing to Confront COPD International Patient Survey. International Journal of Chronic Obstructive Pulmonary Disease, 11, 881-890. https://doi.org/10.2147/COPD.S102280

[54] Stoilkova-Hartmann, A., Franssen, F.M.E., Augustin, I.M.L., Wouters, E.F.M. and Barnard, K.D. (2018) COPD Patient Education and Support-Achieving Patient-Centredness. Patient Education and Counseling, 101, 2031-2036. https://doi.org/10.1016/j.pec.2018.05.024 